http://jmscr.igmpublication.org/home/ ISSN (e)-2347-176x ISSN (p) 2455-0450

crossref DOI: https://dx.doi.org/10.18535/jmscr/v8i3.25

Journal Of Medical Science And Clinical Research

\title{
A Clinico-radiological presentation of smear positive pulmonary tuberculosis in elderly patient in tertiary care hospital of Bikaner, Rajasthan
}

\author{
Authors \\ Dr Ankit Kumar Tiwari ${ }^{1}$, Dr Anil Sobti ${ }^{2}$, Dr Ujjwal Sourav ${ }^{3 *}$ \\ ${ }^{1}$ Resident Doctor, Dept of Internal Medicine, Kothari Medical and Research Institute , Bikaner, Rajasthan \\ ${ }^{2}$ Head of Dept, Dept of Internal Medicine, Kothari Medical and Research Institute, Bikaner, Rajasthan \\ ${ }^{3}$ Asst Professor, Dept of Community Medicine, Saraswathi Institute of medical Sciences, Hapur, UP \\ *Corresponding Author \\ Dr Ujjwal Sourav
}

Asst Professor, Dept of Community Medicine, Saraswathi Institute of medical Sciences, Hapur, UP, India Abstract

Introduction: With an increase in geriatric population, also an increase in the incidence of tuberculosis seen in elderly, the burden of tuberculosis is bound to increase in the country

Aim \& Objective: To study the clinical and radiological profile of sputum +ve, pulmonary tuberculosis in elderly subjects.

Material \& Methods: It was the descriptive longitudinal study conducted on 110 patients during the time span from May 2019 to Feb 2020. All patients having symptoms suggestive of pulmonary tuberculosis were subjected to sputum smear for AFB examination, Mantoux test, $X$ ray chest $P A$ view and haematological investigations. Clinico and Radiological profile were studied.

Result: Prevalence of fever and Anorexia (70.9\%), Wt loss (80\%), Cough (78.2\%) were more prominent clinical symptoms whereas haemoptysis (11.8\%), Dyspnoea (30.9\%), chest pain(20.9\%) were relatively less prevalent symptoms in elderly patients. In our study the radiological features shows bilateral involvement, Moderate disease and upper zone involvement were most frequently found in elderly patients. Only $28.2 \%$ study subjects had cavitory lesions.

Conclusions: Prevalence of fever and Anorexia, Wt loss, Cough were more prominent clinical symptoms whereas haemoptysis, Dyspnoea, chest pain were relatively less prevalent symptoms in elderly patients. radiological features shows bilateral involvement, Moderate disease and upper zone involvement were most frequently found in elderly patients.

Keywords: Tuberculosis, Geriatrics, Mantoux test.

\section{Introduction}

Tuberculosis continues to be a major public health problem causing ill health to approximately 10 million people each year. It is 1 of the 10 causes of death worldwide from a single infectious agent, causing an estimated 1.3 million deaths among human immunodeficiency virus (HIV)- negative people in 2017. India, according to the World
Health Organization (WHO), is considered one of the high-burden countries for tuberculosis (TB), with an estimated total TB incidence of 204/100,000 and mortality of 31 per 100,000 population. ${ }^{(1)}$

Government of India adopted "National Policy on Older Persons" which defines "senior citizen" or "elderly" as a person who is of age 60 years or above. By 2025, the number of elderly people is expected to rise more than 1.2 billion with about 
840 million of these in developing countries. With an increase in geriatric population, also an increase in the incidence of tuberculosis seen in elderly, the burden of tuberculosis is bound to increase in the country $^{(2)}$

The biological changes associated with aging, associated malnutrition and acute or chronic diseases have been reported to disrupt protective barriers, contribute to the expected age-related diminution in cellular immune responses and impair microbial clearance mechanisms against Mycobacterium TB. In addition of these, the increased incidence of adverse drug reactions makes the treatment extremely difficult and challenging in geriatric age group patients. ${ }^{(3)}$

With this background this study was planned to study the clinical and radiological profile of sputum + ve, pulmonary tuberculosis in elderly subjects.

\section{Materials and Methods}

This study was conducted at Department of Internal Medicine, Kothari medical and research institute Bikaner, India. It is a tertiary care hospital. It was the descriptive longitudinal study conducted on 110 patient during the time span from May 2019 to Feb 2020. Ethical clearance was taken from the ethical committee of the Institute. All patients having symptoms suggestive of pulmonary tuberculosis were subjected to sputum smear for AFB examination, Mantoux test, $\mathrm{X}$ ray chest $\mathrm{PA}$ view and haematological investigations.

We included only smear positive newly diagnosed pulmonary tuberculosis patients. Two radiologists who were aware of the diagnosis but not clinical history reviewed the initial radiographs. The radiological evaluation was simple enough as to consider that potential biases, if any, were relatively small. The tubercular lesions were classified according to the site of lesion (unilateral, bilateral) and extent of lesion. Extent of lesion again divided in three, minimal lesion: disease with a combined area of less than that of the right upper lobe. Moderately advanced: Disease with a combined area of less than that of the right lung but more than that of the right upper lobe. Far advanced: Disease with a combined area of more than that of the right lung. The upper and lower lung fields defined as the lung above and below the hilar level respectively. Cavitation was considered to be present only when its diameter was more than $2 \mathrm{cms}$. Diabetes mellitus, chronic liver diseases, asthma, chronic renal failure, and HIV were noted as well. Any relevant past history and personal history including dietary habits, smoking, alcohol, and other addictions were also taken. Record of the radiological reading interms of consolidation, nodular opacity, and cavitation were also noted. Presence of pleural effusion, pneumothorax, fibrosis, and hilar lymphadenopathy was also noted. Inclusion criteria:

All cases of smear positive pulmonary tuberculosis cases are studied in detail as per Performa Patients above the age of 60 years are considered as Elderly.

Exclusion Criteria

1) Smear negative cases

2) Extra pulmonary tuberculosis,

3) Tuberculosis with HIV

4) Tuberculosis with pregnancy

\section{Results}

The study comprised 110 patients, The demographic profile shows the mean age of patients was $68.57 \pm 3.07$ yrs. Male predominance $(70.9 \%)$ was seen, $73.64 \%$ subjects were urban. $82.73 \%$ study subjects were Hindu.

The co-morbidities such as HTN was seen in $21.8 \%$, COPD was in $23.6 \%$, and malignancies was seen in $8.18 \%$ of elderly patients. Prevalence of fever and Anorexia (70.9\%), Wt loss (80\%), Cough (78.2\%) were more prominent clinical symptoms whereas haemoptysis (11.8\%), Dyspnoea (30.9\%), chest pain $(20.9 \%)$ were relatively less prevalent symptoms in elderly patients.

In our study the radiological features shows bilateral involvement, Moderate disease and upper zone involvement were most frequently found in elderly patients. Only $28.2 \%$ study subjects had cavitory lesions. 
Table 1: Demographic characteristics of the elderly pulmonary tuberculosis patients

\begin{tabular}{|l|c|c|}
\hline $\begin{array}{l}\text { Demographic } \\
\text { characteristics }\end{array}$ & No & $\%$ \\
\hline Age (mean \pm SD) & $68.57 \pm 3.07 \mathrm{yrs}$ & \\
\hline Gender & & \\
\hline Male & 78 & 70.9 \\
\hline Female & 32 & 29.1 \\
\hline Residence & & \\
\hline Urban & 21 & 73.64 \\
\hline Rural & & 26.36 \\
\hline Religion & 91 & \\
\hline Hindu & 19 & 82.73 \\
\hline Other than Hindu & \multicolumn{2}{|l}{} \\
\hline
\end{tabular}

Table 2: Co-morbidities of the elderly pulmonary tuberculosis patients

\begin{tabular}{|l|c|c|}
\hline Co-morbidity & No & \% \\
\hline Diabetes melitus & 11 & 10 \\
\hline Hypertension & 24 & 21.8 \\
\hline COPD & 26 & 23.6 \\
\hline Malignancy & 9 & 8.18 \\
\hline Chronic kidney disease & 3 & 2.73 \\
\hline
\end{tabular}

Table 3: Symptomatology of pulmonary tuberculosis in elderly patients

\begin{tabular}{|l|c|c|}
\hline Symptoms & No & \% \\
\hline Cought and /or sputum & 86 & 78.2 \\
\hline Hemoptysis & 13 & 11.8 \\
\hline Fever & 78 & 70.9 \\
\hline Night sweats & 21 & 19.1 \\
\hline Weight Loss & 88 & 80 \\
\hline Anorexia & 78 & 70.9 \\
\hline Chest pain & 23 & 20.9 \\
\hline Dyspnea & 34 & 30.9 \\
\hline
\end{tabular}

Table 4: Radiological and laboratory findings in elderly pulmonary tuberculosis patients

\begin{tabular}{|l|c|c|}
\hline Radiological Lesion & No & $\%$ \\
\hline Site of lesion & & \\
\hline Unilateral & 44 & 40 \\
\hline Bilateral & 66 & 60 \\
\hline Extent of Lesions & & \\
\hline Minimal & 23 & 20.9 \\
\hline Moderate & 47 & 42.7 \\
\hline Far advance & 40 & 36.4 \\
\hline Involvement of zone & & \\
\hline Upper zone & 46 & 41.8 \\
\hline Lower zone & 26 & 23.6 \\
\hline Multiple zone & 28 & 25.6 \\
\hline Cavitatory lesion & & \\
\hline Yes & 31 & 28.2 \\
\hline No & 79 & 71.8 \\
\hline
\end{tabular}

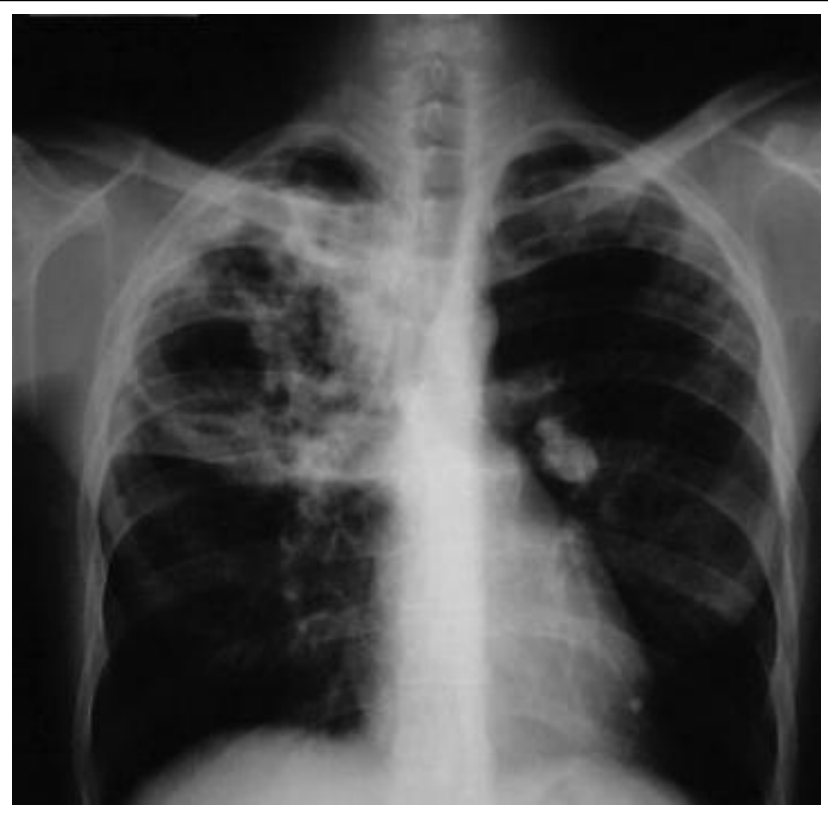

Fig 1 Chest X-ray showing Upper lobe involvement

\section{Discussion}

Despite extensive tuberculosis control efforts in the past by WHO and local health departments, the tuberculosis epidemic continuous to ravage the developing world; affecting all susceptible individuals including aging adult. Several factors such as increase in the elderly population, immunocompromised host, patients on steroids, anti-cancer drugs and immunosuppressive drugs and reactivation of dormant infection have contributed to this increasing proportion of TB in elderly.

In relation to the gender of the patients, we found that male predominance was there. Other studies such as, Singh SK et $\mathrm{al}^{(4)}$ shows $62 \%$ female, however Rawat $\mathrm{J}$ et al ${ }^{(5)}$ shows almost similar male predominance i.e $74 \%$ male was reported similar. One possible explanation for this male predominance may be that in most countries men usually have more social and labour activities than women, thus favouring the transmission of the disease.

In our study, elderly tuberculosis patients had significantly higher occurrence of comorbidities like hypertension, COPD, malignancy and diabetes. These results correspond to those of Rawat $\mathbf{J}$ et al ${ }^{(5)}$, Alvarez et $\mathrm{al}^{(6)}$, Umeki et $\mathrm{al}^{(7)}$, Vanden Brande ${ }^{(8)}$. The exact relationship between these disorders and disease produced by $\mathrm{M}$. tuberculosis is not fully 
understood because none of the studies include control non-tubercular group.

Our data suggest that symptoms like Prevalence of fever and Anorexia (70.9\%), Wt loss (80\%), Cough (78.2\%) were more prominent clinical symptoms whereas hemoptysis, chest pain and night sweats occurred in lesser study subjects. The above results are in agreement with those of others such as. Umeki et $\mathrm{al}^{(7)}$ and Vanden Brande et $\mathrm{al}^{(8)}$ also reported similar results, However, differences in symptoms frequencies between these studies and the present study may be explained by earlier pulmonary TB detection by mass survey in former studies

As for roentgenographic abnormality, in the present study, a higher involvement of upper lung field, more moderate lesion and less frequent cavitations were observed in the elderly patients. There had been much debate concerning the atypical radiographic findings of $\mathrm{TB}$ in the elderly. Some have reported no major differences ${ }^{12,13}$ while other have reported a higher involvement of the middle and lower lung fields in the elderly ${ }^{7,8,19}$. Our findings are consistent with those of Perez ${ }^{9}$ and chan 10 et al in this respect. It has been suggested that the higher frequency of upper lung disease and less cavity formation in the elderly is due to immunologic abnormalities, higher frequency of primary tuberculosis.

\section{Conclusion}

In our study The co-morbidities such as HTN, COPD malignancies were common in elderly patients. Prevalence of fever and Anorexia, Wt loss, Cough were more prominent clinical symptoms whereas haemoptysis, Dyspnoea, chest pain were relatively less prevalent symptoms in elderly patients.

In our study the radiological features shows bilateral involvement, Moderate disease and upper zone involvement were most frequently found in elderly patients.

Conflict of Interest: NA

Funding: No

\section{References}

1. Kilaru SC, Prasad S, Kilaru H, Anneela RR, Hasan A, Nandury EC. Active pulmonary tuberculosis presenting with acute respiratory failure. Respirol Case Reports. 2019;7(7):1-5.

2. Kumar M, Head U, Medicine $\mathrm{R}$. International Journal Of Scientific Research Comparative Study Of Clinico-Radiological Profile Of Pulmonary Tuberculosis In New And Previously Treated Patients Of Geriatric. 2018;49(6):13-5.

3. Kalra DK. A Comparative Study on Elderly PulmonaryTuberculosis Patients on the Basis of Radiological \& Microbiological findings in aTertiary Care Teaching Hospital. Int Arch BioMed Clin Res. 2019;5(3):80-82.

4. Singh SK, Tiwari KK. Clinicoradiological Profile of Lower Lung Field Tuberculosis Cases among Young Adult and Elderly People in a Teaching Hospital of Madhya Pradesh, India. J Trop Med. 2015;2015(4):15.

5. Rawat J, Sindhwani G, Juyal R. Clinico radiological profile of new smear positive pulmonary tuberculosis cases among young adult and elderly people in a tertiary care hospital at Deheradun (Uttarakhand). Indian J Tuberc. 2008;55(2):84-90.

6. Alvarez S, Shell C, Berk SL. Pulmonary tuberculosis in elderly men. Am J Med 1987;82:602-6.

7. Umeki S. Comparison of younger and elderly patients with pulmonary tuberculosis. Respiration 1989;55:75-83.

8. Van den Brande P, Vernies T, Verwerfit J,Van Bleyenber R, Van-hoenacker F, Demedts $\mathrm{M}$. Impact of age and radiographic presentation on the presumptive diagnosis of pulmonary tuberculosis. Respir Med 2002;96:979-83

9. J.-Y.Wang, P.-R. Hsueh, C.-H. Lee et al., "Recognising tuberculosisin the lower lung field: an age- and sex-matched controlledstudy," International Journal of 
Tuberculosis and Lung Disease, 2006;10

(5):pp. 578-584.

10. Jain $\mathrm{S}$ et al, Socio-economical and Clinico Radiological Profile of 474 MDRTB Cases of a Rural Medical College.Journal of The Association of Physicians of India.2018;66:14-18.

11. Gupta S, Bandyopadhyay D, Gupta S, Sadhukhan S, Banerjee S.A sociodemographic study of multidrug resistant tuberculosis cases from DOTS clinics of Kolkata. J Indian Med Assoc 2012; 110:723-5. 